\title{
ТОЧНАЯ ХРОМАТОГРАФИЯ - И НИЧЕГО ЛИШНЕГО
}

\section{Рассказывает главный специалист по хроматографии и масс-спектрометрии компании ООО "Остек-АртТул" М.Г.Балакина}

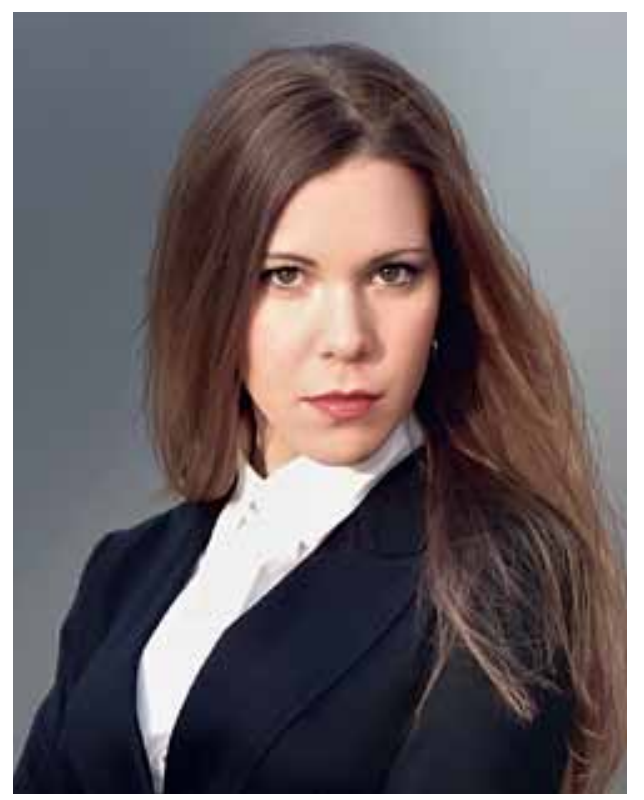

\begin{abstract}
Компания ООО "Остек-АртТул", входящая в Группу компаний Остек, хорошо известна на рынке оборудования для производства электроники и микроскопии. В январе 2017 года компания стала эксклюзивным дистрибьютором в России продукции южнокорейской фирмы YL Instruments, в частности газовых и жидкостных хроматографов, а также масс-спектрометров. О том, какими преимуществами обладают данные приборы для российских заказчиков, каких успехов уже достигла компания на этом новом для себя поле за прошедший год, а также о тенденциях в области хроматографического оборудования мы поговорили с главным специалистом по хроматографии и масс-спектрометрии ООО "Остек-АртТул" Мариной Григорьевной Балакиной.
\end{abstract}

\section{Марина Григорьевна, направление аналитической} химии достаточно новое для вашей компании. Как появилась идея шагнуть в эту область?

Несколько лет назад в компании "Остек-АртТул" возникло направление научно-исследовательского оборудования. Изначально это были решения для электронной микроскопии, точного анализа поверхностей электронно-лучевыми методами, зондовой микроскопии и т. п. Это направление оказалось успешным, и, посетив два года назад выставку analytica в Мюнхене и почувствовав, что рынок аналитического оборудования может быть интересным для нас, представители нашей компании решили дополнить линейку по- ставки научно-исследовательского оборудования хроматографией. Этому решению также способствовал тот факт, что, несмотря на то, что на нашем рынке представлены хроматографы различных производителей, основнуюего долюделят две компании - американская и японская, а в условиях санкций работа с производителями из этих стран может быть затруднена. На этой выставке "Остек-АртТул" обратил внимание на компанию из Южной Кореи - YL Instruments - лидера среди производителей аналитического оборудования на своем внутреннем рынке. С одной стороны, поставка южнокорейского оборудования не связана с санкционными сложностями, а с другой - было видно, что продукция 
данной фирмы обладает хорошим конкурентным потенциалом для российского рынка как по характеристикам и качеству, так и по цене. Следующим шагом стало более близкое знакомство с этой фирмой. Специалисты "Остек-АртТул" не раз ездили на завод-производитель, общались с руководством, с инженерами. В результате стало очевидно, что это хороший выбор: помимо параметров оборудования, на высоком уровне оказались и техническая поддержка, и организация поставок, и гарантийное обслуживание. Иными словами, добросовестность поставщика была подтверждена.

я хотела бы отметить, что эта история случилась до моего прихода в "Остек-АртТул", который, по сути, стал следующим этапом развития событий. Группа компаний Остек имеет большой опыт в поставке передового оборудования и технологий на отечественный рынок и всегда была ориентирована на то, чтобы продавать не просто приборы, но и знания и компетенции. А это немыслимо без профильных специалистов в своей команде. Мое образование - химический факультет МГУ им. М.В.Ломоносова по направлению хроматографии - и мой предыдущий опыт работы в точности соответствовали поставленной задаче и, надеюсь, уже оказались полезными для развития этого направления в компании "Остек-АртТул".

И, наконец, мы подошли к самому главному этапу - продвижению практически нового бренда на российском рынке. Я говорю "практически", потому что хроматографы YL Instruments до этого в Россию поставлялись, но продвижение было недостаточным, бренд был почти неизвестен. Кроме того, такое оборудование нельзя продавать, как, например, стиральные машины - просто по запросу: хроматографы отличаются большим количеством комплектующих, расходных материалов, и во всем этом необходимо глубоко разбираться, чтобы предоставить заказчику именно то решение, которое ему нужно. Можно сказать, что хроматография - это уникальное аналитическое решение в том смысле, что она применяется в широчайшем спектре областей от нефтехимии и экологии до пищевой промышленности, медицины и фармацевтики и позволяет исследовать вещества в различных агрегатных состояниях - твердые, жидкие, газообразные. Поэтому, чтобы сделать это оборудование привлекательным для заказчиков и узнаваемым на рынке, нужно оказывать очень хорошую поддержку.

Так что, нам предстояло проделать большую работу.

\section{И каких результатов удалось достичь за это время?}

Мы являемся эксклюзивным дистрибьютором YL Instruments в России чуть больше года. Но могу сказать, что интерес к продукции YL Instruments превзошел наши ожидания. Конечно, еще нельзя сказать, что у нас много клиентов по этому направлению: для этого необходима более длительная история. Плюс, сказывается некоторая осторожность нашего рынка по отношению к корейскому оборудованию. Это чем-то похоже на то, что происходило с корейскими автомобилями: долгое время многие люди предпочитали им отечественные либо, например, подержанные немецкие или японские марки просто потому, что о корейских машинах мало что было известно. Но ведь эта ситуация изменилась.

Сейчас к нам приходит много запросов - больше, чем мы изначально ожидали. Также мы видим высокий интерес со стороны компаний, которые уже занимаются продажами аналитического оборудования на рынке, к тому, чтобы включить в свою линейку и наше предложение. Это - шаг к организации дилерской сети. И мы видим в этом хорошие перспективы, поскольку хроматографы компании YL Instruments обладают высокой конкурентной способностью по соотношению цены и качества.

Вы сказали, что хроматография имеет очень широкий спектр применений. На какие рынки вы в первую очередь ориентируетесь?

Конечно, самый большой и, так скажем, финансово обеспеченный рынок - это нефтехимия. Кроме того, для нас очень интересна пищевая промышленность: там хроматография тоже очень востребована.

Мы рассматриваем и другие рынки, такие как медицина, фармацевтика, разработка биологически активных добавок. В особенности в последней области интерес к хроматографии достаточно высок, поскольку там ведется множество экспериментальных работ. Но в этих областях не так много готовых универсальных решений, и каждый клиент требует особого внимания. Кроме того, постоянно меняются стандарты. Если сравнивать с нефтехимией, где, например, анализ топлива - уже отработанная процедура, применяемая многие годы, фармацевтика - гораздо более сложный рынок.

Группа компаний Остек хорошо известна прежде всего на рынке производства электроники. Не возникает ли сложностей с выходом на совершенно другие рынки?

И да, и нет. Да - потому что к задаче продвижения нового бренда YL Instruments добавляется задача продвижения и нашего собственного бренда. Но в то же время Остек - это идеально отточенный инструмент маркетинга, продвижения импортного оборудования на российском рынке. Это, можно сказать, окно в Россию для любых зарубежных технологий - главное, чтобы они были качественные и нужные. Я, как относительно новый сотрудник Остека, чувствую поддержку и опыт, которые стоят за моей спиной в отношении продвижения таких решений, в том, как выстроить сервис, поддержку, обеспечить высокое качество услуг и в результате достичь удовлетворенности заказчика на любом рынке. 
Действительно, хроматография несколько нетипична для основного спектра продукции, поставляемой Остеком, но она практически полностью вписывается в те подходы, которые использует компания для успешного продвижения других технологий в России. Остается только дополнить эти общие подходы поддержкой, специфичной именно для хроматографии, - и это моя задача, как специалиста в данной области.

Остек всегда был ориентирован на то, чтобы предоставить клиенту готовое решение. Никто не хочет получить прибор, который нужно дорабатывать, доукомплектовывать, к которому нужно искать расходные материалы и т. п. Поэтому и в области хроматографии мы стремимся поставлять все необходимое. Мы подбираем конфигурацию под нужды заказчика, поставляем расходные материалы, обеспечиваем техническую поддержку, выполняем плановое и внеплановое обслуживание. Если заказчику необходима аттестованная методика, мы организуем ее разработку и аттестацию в аккредитованных центрах и институтах согласно действующему законодательству.

Так что, умение предоставлять готовые решения вне зависимости от вида продукции - сильная сторона Остека, благодаря которой выход на новые рынки для нас не так сложен.

\section{Мы ориентированы на mo, 4moбbl предоставлять}

\section{кичентам 20moвые}

\section{решения}

Кстати, стоит отметить, что "Остек-АртТул" открывает окно и для российских технологий за рубеж. Есть российские компании, которые предлагают интересные решения, но не обладают ресурсами или опытом для выхода на зарубежные рынки. И у нас есть подразделение, которое помогает в этом таким компаниям.

С кем вам приходится конкурировать в первую очередь?

Наш основной конкурент - российский производитель. Bo-первых, для него, так же как и для YL Instruments, не существует проблемы санкций, а во-вторых - мы близки по ценам.

В России существует парк хроматографов, которые работают уже достаточно давно, и их пользователи, как правило, не хотят переходить на решения от другого производителя: они привыкли к интерфейсу прибора, к программному обеспечению (ПО) и т. п. Поэтому наши заказчики - это обычно те, кто приобретают хроматограф впервые. А у таких компаний часто нет достаточного опыта, им необходима помощь. Мы такую помощь можем предоставить: научить их работать с оборудованием, разработать методику, познакомить с ПО, помочь получить стабильность результатов - все это дает нам сильное конкурентное преимущество.

Но и в том случае, если в компании используются американские или японские хроматографы, у нас есть аргументы, чтобы убедить ее перейти на поставляемое нами оборудование.

Одно из привлекательных качеств установок YL Instruments - ремонтопригодность и простота обслуживания. Но это вовсе не означает, что их приходится часто ремонтировать: это оборудование очень надежное. Более того, YL Instruments является единственным на сегодняшний день производителем хроматографов, который дает на свою продукцию трехлетнюю заводскую гарантию.

Конечно же, и про уже упомянутые санкции нельзя забывать. Стоит отметить, что у корейского производителя нет никаких проблем и ограничений с поставками также и на территорию Крыма.

Если говорить о технических характеристиках хроматографов YL Instruments, как они соотносятся с параметрами более дорогих конкурентов? Означает ли приобретение корейского хроматографа за меньшую цену, чем, скажем, американского или японского, некоторый компромисс в отношении этих характеристик?

По техническим параметрам хроматографы YL Instruments полностью соответствуют передовому уровню, поэтому говорить о компромиссе в отношении характеристик не приходится. Если вновь провести сравнение с автомобилями, приобретение более дорогого хроматографа похоже на покупку машины с массой дополнительных опций: различных электронных устройств, дорогой аудиосистемой, дорогой отделкой салона. Это все не влияет ни на ходовые качества, ни на надежность, а в некоторых случаях даже может усложнить уход и увеличить затраты на эксплуатацию. Конечно, нельзя говорить, что дополнительные опции - всегда плохо, но выбирать их нужно с умом, не забывая об основном предназначении изделия, будь то автомобиль или хроматограф.

Кроме того, нужно понимать, что в современных хроматографах некоторые узловые части - покупные, сторонних производителей. Их изготавливают специализирующиеся в данных областях компании, и в хроматографах от различных компаний и разных ценовых категорий 
могут стоять одни и те же агрегаты. Например, это относится к элементам вакуумной системы.

В общем, можносказать, чтохроматографыYLInstruments удовлетворяют потребностям российских заказчиков и современным российским и международным стандартам.

Что же включает в себя линейка хроматографов YL Instruments?

YL Instruments производит два типа хроматографов: газовые и жидкостные. Кроме того, газовый хроматограф может комплектоваться масс-спектрометрическим детектором. Большинство действующих российских стандартов и методик направлены на методы газовой хроматографии. Некоторые из нихпредполагают наличие масс-спектрометрического детектора. Поставляемые нами хроматографы полностью удовлетворяют как российским стандартам, так и большинству зарубежных, таких как ASTM.

Для газовой хроматографии YL Instruments предлагает полный спектр инжекторов как для капиллярных, так и для насадочных колонок, а также широкую линейку детекторов. Причем дополнительные детекторы очень просто монтируются - с этим пользователь при желании может справиться самостоятельно. Исключением является масс-спектрометрический детектор, который требует настройки квалифицированным сервисным инженером. Но доукомплектовать газовый хроматограф таким детектором можно, что очень важно, если у компании нет достаточного бюджета для приобретения хроматографа с массспектрометрическим детектором сразу.

Что касается жидкостной хроматографии, приборы YL Instruments также соответствуют всем необходимым стандартам. С 2018 года производитель обновил эти приборы: если раньше автосэмплер располагался отдельно, то в новом исполнении он встроенный. Прибор теперь выглядит, как единая колонка без дополнительных устройств, занимающих место в лаборатории. Для жидкостного хроматографа также предлагаются все необходимые детекторы.

Следует отметить, что ПО хроматографов YL Instruments интуитивно понятное - его легко настроить и им удобно пользоваться. ПО позволяет задавать различные параметры учетной записи вплоть до доступа к данным при помощи электронного ключа и электронной подписи. Это достаточно важно для ряда отраслей, например для фармацевтики.

Приборы на данный момент зарегистрированы в Государственном реестре средств измерений, для них разработаны методики поверки, получены соответствующие сертификаты.

Какие тенденции развития существуют сейчас в области хроматографии и оборудования для этого аналитического метода?
Метод хроматографии имеет длительную историю, и с того момента, как он был открыт в начале 20 века русским ученым Михаилом Семеновичем Цветом, он активно развивался и получал все большее распространение. Но нужно сказать, что за последние лет 30 сам метод практически не претерпел изменений. Меняется оборудование, оно становится всё более точным, совершенствуются детекторы,

\section{Хроматография может} заменить ряд методов,
которые сложно
автоматизировать

уменьшается уровень шумов, снижается предел детектирования, повышается стабильность и воспроизводимость измерений.

В хроматографах используются новые технологии и материалы. Благодаря возможности синтеза новых полимеров увеличена эффективность (разделительная способность) набивных колонок, а также селективность разделения за счет повышенной избирательной способности сорбента. Новые разработки в области электроники существенно увеличили экспрессность разделения веществ вплоть до десятков пиков в секунду. Также разработчиками уделяется большое внимание надежности приборов и их долговечности.

Кроме того, оборудование и программное обеспечение становятся все более эргономичными. Применяются сенсорные дисплеи, интерфейсы становятся все более удобными.

Нужно отметить, что у хроматографии достаточно большой потенциал в отношении автоматизации. Некоторые аналитические методы, которые дают неплохие результаты и соответствуют стандартам, сложно автоматизировать. И зачастую хроматограф может заменить их, выступая в определенной степени универсальным аналитическим прибором, позволяющим подготовить, например, 200-250 проб, загрузить их в установку и через сутки получить результат, который можно будет отобразить в форме удобного отчета с помощью ПО. Поэтому сейчас существует тенденция к тому, чтобы хроматографические методы применялись все шире, что находит отражение и в соответствующих стандартах.

Спасибо за интересный рассказ. СМ.Г.Балакиной беседовап Ю.С.Ковапевский 